\title{
Acute and chronic changes in brain activity with deep brain stimulation for refractory depression
}

DOI:

$10.1177 / 0269881117742668$

\section{Document Version}

Accepted author manuscript

Link to publication record in Manchester Research Explorer

\section{Citation for published version (APA):}

Conen, S., Matthews, J., Anton-Rodriguez, J., Patel, N., \& Talbot, P. (2018). Acute and chronic changes in brain activity with deep brain stimulation for refractory depression. Journal of Psychopharmacology, 32(4), 430- 440. https://doi.org/10.1177/0269881117742668

\section{Published in:}

Journal of Psychopharmacology

\section{Citing this paper}

Please note that where the full-text provided on Manchester Research Explorer is the Author Accepted Manuscript or Proof version this may differ from the final Published version. If citing, it is advised that you check and use the publisher's definitive version.

\section{General rights}

Copyright and moral rights for the publications made accessible in the Research Explorer are retained by the authors and/or other copyright owners and it is a condition of accessing publications that users recognise and abide by the legal requirements associated with these rights.

\section{Takedown policy}

If you believe that this document breaches copyright please refer to the University of Manchester's Takedown Procedures [http://man.ac.uk/04Y6Bo] or contact uml.scholarlycommunications@manchester.ac.uk providing relevant details, so we can investigate your claim.

\section{OPEN ACCESS}


Journal of

Psychopharmacology

\section{Acute and chronic changes in brain activity with deep brain stimulation for refractory depression}

\begin{tabular}{|c|c|}
\hline Journal: & Journal of Psychopharmacology \\
\hline Manuscript ID & JOP-2017-3199.R1 \\
\hline Manuscript Type: & Original Paper \\
\hline Date Submitted by the Author: & $\mathrm{n} / \mathrm{a}$ \\
\hline Complete List of Authors: & $\begin{array}{l}\text { Conen, Silke; University of Manchester, Division of Neuroscience and } \\
\text { Experimental Psychology } \\
\text { Matthews, Julian; University of Manchester, Division of Informatics, } \\
\text { Imaging \& Data Sciences } \\
\text { Patel, Nikunj; Frenchay Hospital, Department of Neurosurgery } \\
\text { Anton-Rodriguez, José; University of Manchester, Division of Informatics, } \\
\text { Imaging \& Data Sciences } \\
\text { Talbot, Peter; University of Manchester, Division of Neuroscience and } \\
\text { Experimental Psychology }\end{array}$ \\
\hline \multirow[t]{2}{*}{$\begin{array}{r}\text { Please list at least } 3 \text { keywords } \\
\text { which relate to your } \\
\text { manuscript: }\end{array}$} & $\begin{array}{l}\text { PET, Deep Brain Stimulation, Treatment Refractory Depression, Nucleus } \\
\text { Accumbens, Subgenual Cingulate }\end{array}$ \\
\hline & $\begin{array}{l}\text { Deep brain stimulation (DBS) is a potential option for patients with } \\
\text { treatment-refractory depression (TRD). DBS benefits have been reported } \\
\text { when targeting either the subgenual cingulate (SGC) or ventral anterior } \\
\text { capsule/nucleus accumbens (VAC/NAcc). However, not all patients respond } \\
\text { and optimum stimulation-site is uncertain. We compared DBS of SGC and } \\
\text { VAC/NAcc separately and combined in the same seven TRD patients, and } \\
\text { investigated regional cerebral blood-flow (rCBF) changes associated with } \\
\text { acute and chronic DBS. DBS-response was defined as reduction in } \\
\text { Montgomery-Asberg Depression Rating Scale (MADRS) score from baseline } \\
\text { of } \geq 50 \% \text {, and remission as a MADRS-score } \leq 8 \text {. Changes in rCBF were } \\
\text { assessed using [15O]water PET. Remitters had higher relative rCBF in the } \\
\text { prefrontal cortex (PFC) at baseline and all subsequent time-points } \\
\text { compared to non-remitters and non-responders, with PFC rCBF generally } \\
\text { increasing with chronic DBS. These effects were consistent regardless of } \\
\text { stimulation-site. Overall, no significant rCBF changes were apparent when } \\
\text { DBS was acutely interrupted. DBS improved TRD severity in the majority of } \\
\text { patients, with consistent changes in local and distant brain regions } \\
\text { regardless of target stimulation. Remission of depression was reached in } \\
\text { patients with higher baseline prefrontal rCBF. Because of the small sample } \\
\text { size these results are preliminary and further evaluation is necessary to } \\
\text { determine whether PFC rCBF could be a predictive biomarker of treatment } \\
\text { response. }\end{array}$ \\
\hline
\end{tabular}




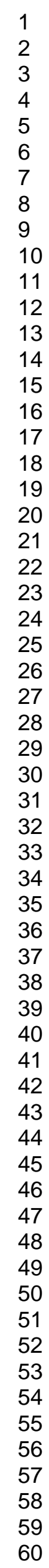

SCHOLARONE ${ }^{m}$

Manuscripts

7

9

10

11

12

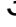

16

17

18

19

20

22

24

26

27

29

32

33

34

35

36

38

39

40

41

42

44

45

46

47

48

50

51

52

55

56

57

58

60

http://mc.manuscriptcentral.com/jop 


\section{TITLE PAGE}

Title: Acute and chronic changes in brain activity with deep brain stimulation for refractory depression

Short Title: Deep brain stimulation in TRD

\section{Silke Conen* ${ }^{\mathrm{a}}$, Julian C. Matthews* ${ }^{\mathrm{b}}$, Nikunj K. Patel ${ }^{\mathrm{c}}$, José Anton-Rodriguez ${ }^{\mathrm{b}}$ and Peter S. Talbot ${ }^{\mathrm{a}}$}

* These authors contributed equally

${ }^{a}$ Division of Neuroscience and Experimental Psychology, School of Biological Sciences, Faculty of Biology, Medicine and Health, University of Manchester, Manchester Academic Health Science Centre, Manchester M13 9PT, UK

${ }^{\mathrm{b}}$ Division of Informatics, Imaging \& Data Sciences, School of Health Sciences, Faculty of Biology, Medicine and Health, University of Manchester, University of Manchester, Manchester Academic Health Science Centre, Wolfson Molecular Imaging Centre, Manchester M20 3L, UK

${ }^{c}$ Department of Neurosurgery, Institute of Neurosciences, Frenchay Hospital, Bristol, United Kingdom

\section{Corresponding author:}

Dr Peter S Talbot MD, MRCPsych

Wolfson Molecular Imaging Centre

27 Palatine Road

Manchester, M20 3L

United Kingdom

Tel: +44 (0) 1612750015

E-mail: peter.talbot@manchester.ac.uk 


\section{ABSTRACT}

Deep brain stimulation (DBS) is a potential option for patients with treatment-refractory depression (TRD). DBS benefits have been reported when targeting either the subgenual cingulate (SGC) or ventral anterior capsule/nucleus accumbens (VAC/NAcc). However, not all patients respond and optimum stimulation-site is uncertain. We compared DBS of SGC and VAC/NAcc separately and combined in the same seven TRD patients, and investigated regional cerebral blood-flow (rCBF) changes associated with acute and chronic DBS. DBS-response was defined as reduction in Montgomery-Asberg Depression Rating Scale (MADRS) score from baseline of $\geq 50 \%$, and remission as a MADRS-score $\leq 8$. Changes in $\mathrm{rCBF}$ were assessed using $\left[{ }^{15} \mathrm{O}\right]$ water PET. Remitters had higher relative $\mathrm{rCBF}$ in the prefrontal cortex $(\mathrm{PFC})$ at baseline and all subsequent time-points compared to non-remitters and non-responders, with PFC rCBF generally increasing with chronic DBS. These effects were consistent regardless of stimulation-site. Overall, no significant rCBF changes were apparent when DBS was acutely interrupted. DBS improved TRD severity in the majority of patients, with consistent changes in local and distant brain regions regardless of target stimulation. Remission of depression was reached in patients with higher baseline prefrontal rCBF. Because of the small sample size these results are preliminary and further evaluation is necessary to determine whether PFC rCBF could be a predictive biomarker of treatment response. 
Deep brain stimulation in TRD

\section{INTRODUCTION}

Major Depressive Disorder (MDD) is a common psychiatric disorder affecting an estimated 350 million people globally. It is severely debilitating and characterized by low mood, decreased energy, impaired cognition, and increased risk of suicide (World Health Organization, 2016). MDD can be effectively treated in the majority of patients with either antidepressant medication or psychotherapy (Mayberg et al., 2005). However, $20-30 \%$ of patients fail to respond to standard therapies (Mayberg et al., 2005; Morishita et al., 2014; Millet et al., 2014).

A possible alternative treatment for this treatment-refractory depression (TRD) is deep brain stimulation (DBS). DBS aims to modulate dysfunctional neuronal networks by surgical placement of stimulating electrodes (Krishnan and Nestler, 2010). Promising antidepressant effects of DBS have been reported when targeting either the subgenual cingulate gyrus (SGC), comprising Brodmann areas 25 (Cg25) and 24 (Cg24) (Berlim et al., 2014; Holtzheimer et al., 2012; Lozano et al., 2008; Mayberg et al., 2005; Puigdemont et al., 2012), or the ventral anterior capsule/nucleus accumbens (VAC/NAcc) (Bewernick et al., 2010; Bewernick et al., 2012; Millet et al., 2014; Nauczyciel et al., 2013; Schlaepfer et al., 2008; Kubu et al., 2013; Malone et al., 2009). These targets are in close anatomical and functional relationship, and data from neuroimaging studies can be used to argue for either of these targets (Schlaepfer and Bewernick, 2013).

Cg25 glucose metabolism is increased in MDD and remission is associated with normalization of this hypermetabolism (Schlaepfer and Bewernick, 2013). DBS of Cg25 has shown a response rate (i.e. at least $50 \%$ reduction in the Hamilton Depression Rating Scale) of $62.5 \%$ after 12 months (Puigdemont et al., 2012), 60\% after three years, and 55\% between 3 to 6 years (Kennedy et al., 2011) of DBS, and is associated with reduced $\operatorname{Cg} 25$ metabolic activity. The NAcc is involved in abnormal motivations 
Deep brain stimulation in TRD

and reward processes in MDD, and NAcc DBS for 1 to 4 years has demonstrated sustained antidepressant effects in $45 \%$ of patients (Bewernick et al., 2012). VAC DBS for up to 4 years has shown a response rate of $40 \%$ at 6 months and $53.3 \%$ at last follow-up (Malone et al., 2009).

However, due to small sample sizes of $<20$ and relatively few studies, it is unclear which of these targets is most effective in producing a positive outcome. Furthermore, even though these targets seem promising, response to DBS does not occur in all patients. Since mood effects are not observed in all patients with either target, it might be possible that combined stimulation of both targets will achieve better clinical results in patients with insufficient response to stimulation of only one target. Additionally, previous studies have focused on either short-term chronic effects after 1 week of DBS in MDD (Schlaepfer et al., 2008), or long-term chronic effects after 3 months to 6 years (Bewernick et al., 2010; Bewernick et al., 2012; Lozano et al., 2008; Mayberg et al., 2005; Millet et al., 2014; Kubu et al., 2013; Malone et al., 2009). Comparison of acute effects that appear within hours with chronic effects would help to clarify possible differences in immediate and adaptive longer-term effects of DBS.

Positron emission tomography (PET) using $\left[{ }^{15} \mathrm{O}\right]$ water allows accurate quantification of regional cerebral blood flow (rCBF). As rCBF and regional metabolism are very closely coupled, $\left[{ }^{15} \mathrm{O}\right]$ water PET is an excellent method for assessing changes in brain-activity over time in circumstances where magnetic resonance imaging (MRI) is relatively contraindicated, such as pertains in DBS due to the presence of indwelling stimulator electrodes. A further advantage of $\left[{ }^{15} \mathrm{O}\right]$ water PET is that the very short (2 minutes) half-life of $\left[{ }^{15} \mathrm{O}\right]$ permits more frequent measurements over the same time duration than [18F]fluodeoxyglucose (FDG) PET for the same radiation exposure, permitting comparison of acute and chronic DBS effects. 
The present study aimed to compare stimulation of SGC (Cg25 or Cg24), VAC/NAcc (VAC or NAcc), and a combination of these targets, in the same TRD patients using $\left[{ }^{15} \mathrm{O}\right]$ water PET, focusing on chronic changes in $\mathrm{rCBF}$ and changes in $\mathrm{rCBF}$ associated with acute interruption of DBS for 2 hours. Choice of stimulation site (SGC or VAC/NACC) was made in a block-randomized, single-blind fashion. Patients received stimulation of this site for at least 3 months before switching stimulation to the other single site for at least 3 months, then switching to the combination of both sites for at least a further 3 months. At each site, if remission occurred or clinical improvement was assessed as sufficient, stimulation site was not switched. Secondary outcome measures included clinical questionnaires to characterize effects of DBS on depressive symptoms and functional outcomes.

We hypothesized that: (i) either DBS target would produce a significant improvement in some TRD patients; (ii) combined stimulation would be effective in patients for whom one target was not sufficient; (iii) acute and chronic changes in rCBF associated with DBS would be prominent and would differ from each other; and (iv) clinical improvement would be associated with rCBF changes in brain regions relevant to depression. 
Deep brain stimulation in TRD

\section{METHODS AND MATERIALS}

\subsection{Patients}

Eight patients were enrolled to the study, had pre-surgical measurement of baseline rCBF and implantation of DBS electrodes (see Table 1 for demographics and clinical characteristics). One patient required early removal of electrodes due to infection and was withdrawn from the study before first follow-up PET scan. Therefore, seven patients with treatment refractory unipolar MDD (5 male; age range $31-58$ years; mean \pm SD: $48 \pm 9$ years) received $\left[{ }^{15}\right.$ O]water PET (pre-surgical and three subsequent occasions during DBS). Patient-suitability was jointly assessed by a senior psychiatrist (ALM) and neurosurgeon (NKP) at the University of Bristol, UK. Referrals came from the patients' psychiatric team who were aware of the protocol but not directly involved in the study. If there were any doubts on inclusion criteria, further opinion was sought from one of a panel of three senior psychiatrists who interviewed patients separately.

--- Table 1 ---

Patients were included if they had MDD and had not responded to treatments including: (i) cognitive behavioral therapy (CBT); (ii) antidepressants from three different classes in British National Formulary doses (Committee, 2015); and (iii) lithium augmentation. Furthermore, patients had to have failed to respond to two courses of electroconvulsive therapy (ECT), or to only have responded to maintenance ECT, or to not have responded to the first course of ECT and were unwilling to have a further course. ; and (iv) courses of electroconulsive therapy (ECT). They were required to have a MADRS score of $\geq 22$ (moderately-severely depressed) on enrolment. Additional inclusion criteria were being physically fit_, and having no suicidal intent, history of hypomania, mania nor psychosis. Exclusion criteria included: history of head trauma, dementia, cerebral infarcts, poor 
Deep brain stimulation in TRD

physical health, incapacity to consent, inability to carry out the study, mood incongruent psychotic phenomena, and drug or and/alcohol addiction.

Enrolment and clinical procedures were conducted at the University of Bristol, and MRI and neurosurgery were conducted at Frenchay Hospital, Bristol. PET-scanning was performed at the University of Manchester's Wolfson Molecular Imaging Centre. The study was approved by the Bath Local Research Ethics Committee and the United Kingdom Administration of Radioactive Substances Advisory Committee, and was carried out in compliance with the Declaration of Helsinki (1964), amended in Edinburgh (2000). Participants gave their written informed consent prior to study participation.

\subsection{Surgical Procedure}

The surgical procedure was performed under general anesthesia, using a modified Leksell stereotactic frame (Elekta, Stockholm, Sweden). Patients were implanted with four deep brain stimulating electrodes (Model 3387, Medtronic, Minneapolis, Minnesota): two electrodes were bilaterally positioned with all four contacts in the white matter of the SGC (Cg25 and Cg24), and two electrodes were bilaterally positioned with two contacts in the VAC and two distal contacts in the $\mathrm{NAcc}, 5 \mathrm{~mm}$ anterior to the anterior commissure. Subclavicar programmable neurostimulators were implanted, either non-rechargeable (Kinetra; 7428) or rechargeable (Activa RC; 37601).

DBS electrode positioning and planning was made on high-resolution MRI. Implantable guide tubes and stylettes were stereotactically implanted to the planned coordinates. DBS leads were introduced down the implanted guide-tubes into the targets replacing the stylettes, whose position was verified on perioperative high-resolution MRI, enabling accurate knowledge of the electrode contacts within 
the target (Khan et al., 2010; Patel et al., 2007) (Figure 1). Following the operation, a period of oneweek recovery was allowed to minimize any effect from post-operative edema.

\section{--- Figure 1 ---}

\subsection{Stimulation procedures}

\section{Overview of treatment-periods}

For each patient, DBS was given in three sequential treatment-periods over a total period ranging from 16 to 45 months. The exact duration was determined by each patient's clinical response and requirements. During each period (both sites singly and in combination) DBS was administered bilaterally for at least three months before switching (Table 2). More precisely, the treatmentperiods were as follows:

Treatment-period 1: After post-operative recovery, appropriate stimulation contacts and frequencies were assessed for either SGC (selection of either Cg25 or Cg24) or VAC/NAcc (selection of either VAC or NAcC). The choice of SGC or VAC/NAcC as first stimulation site was made in a block-randomized fashion.

Treatment-period 2: After at least three months, stimulation was switched to the alternate site unless the patient had achieved remission (MADRS score $\leq 8$ for at least two months). Specifically, if during the first stimulation block the SGC (either Cg25 or Cg24) was stimulated, stimulation would now be moved to either VAC or NAcc, and vice versa.

Treatment-period 3: After a further minimum of three months, patients received DBS of a combination of targets unless they had achieved remission in one of previous treatment-periods. 


\section{Criteria for determining stimulation sites and frequencies}

Appropriate stimulation contacts and frequencies were assessed over a period of up to two weeks. Each contact was tried in turn for up to two days. Final selection was the contacts showing most improvement on a mood-diary and a blinded mental-state examination. Stimulation was always bilateral. Patients were blind to order of stimulation, to contacts selected, and to any 'off' period in the contact selection-process.

\subsection{Clinical assessments}

Secondary outcome measures of depressive symptoms and function comprised the MontgomeryAsberg Depression Rating Scale (MADRS) (Montgomery and Asberg, 1979), Hamilton Depression Rating Scale 17 items (HAM-D 17) (Hamilton, 1960), and Global Assessment of Function Scale (GAF) (Hall, 1995). Both the MADRS and HAM-D measure severity of depression, with lower scores indicating lower severity. For the GAF, higher scores indicate less impaired social, occupational, and psychological functioning.

Response to DBS was defined as a reduction in MADRS score from baseline of $\geq 50 \%$, and remission as a MADRS score of $\leq 8$. The delay between clinical assessments and PET scans was as short as practicable, given that they were conducted in different cities, but not more than 72 hours.

\subsection{Image acquisition}

A baseline, pre-operative, high-resolution $T_{1}$-weighted image was acquired using a $1.5 \mathrm{~T}$ Philips Achieva scanner. PET imaging was performed using a High-Resolution Research Tomograph 
(Siemens). $\left[{ }^{15} \mathrm{O}\right]$ water PET scans were acquired at baseline and at the end of each treatment-period. At baseline, 4 repeat scans were acquired in each patient. For each of the other three PET scan visits, 3 repeat scans were acquired when stimulation was switched on and 3 when stimulation had been switched off for 120 minutes (Table 2).

Each scan consisted of an intravenous injection of approximately $370 \mathrm{MBq}$ of $\left[{ }^{15} \mathrm{O}\right]$ water using a radio water generator (HIDEX, Turku, Finland). The data over the 90 second period following activityarrival in the brain was acquired and reconstructed using 3D ordinary Poisson ordered subset expectation maximization (OSEM3D-OP) with 16 subsets and 4 iterations (Comtat et al., 2004). The images were subsequently used as a relative surrogate for $\mathrm{rCBF}$. Scans were spaced a minimum of 10 minutes apart to ensure that radioactivity from the previous scan had decayed to background level.

\subsection{Image pre-processing}

Pre-processing was performed using SPM8 (Statistical Parametric Mapping, Wellcome Department of Imaging Neuroscience, Institute of Neurology, London, UK). For each patient, PET scan images were realigned to each other and used to create a mean image (rigid body, $5 \mathrm{~mm}$ FWHM preregistration smooth). This mean image was then used to co-register subjects PET data to the subject's $T_{1}$-weighted image (rigid body, normalised mutual information) which in turn was spatially normalised to the standard $\mathrm{T}_{1}$-weighted MNI PET template in SPM8 (ICBM regularised affine + nonlinear (frequency cut-off=25, iterations=16, regularisation=1)). Subsequently each PET image was resliced into $2 \mathrm{~mm}$ isotropic voxel $\mathrm{MNI}$ space images and smoothed with a $6 \mathrm{~mm}$ FWHM Gaussian kernel.

\subsection{Data analysis}


Deep brain stimulation in TRD

Whole-brain analysis was performed within SPM8 using a flexible factorial design with interactions between target ( $\mathrm{Cg} 25, \mathrm{Cg} 24, \mathrm{VAC}$, NAcc, combination of $>1$ target stimulated) and activation state (baseline, stimulation on, stimulation off). Clusters of voxels were considered significant at a familywise error (FWE) corrected cluster-size threshold of pFWEc $<0.05$ and a height threshold of pFWE $<0.05$. Follow-up analysis tested: (i) chronic effects of SGC $(\mathrm{Cg} 25+\mathrm{Cg} 24), \mathrm{VAC} / \mathrm{NAcc}$ $(\mathrm{VAC}+\mathrm{NAcc})$, and combined target stimulation, regardless of whether stimulation was switched on or off; and (ii) changes in rCBF between baseline and last PET scan, irrespective of stimulation site and whether stimulation was on or off.

Furthermore, region data were visually inspected by focusing on intensity-normalized data, i.e. voxels which changed relative to average values in the brain (regional/global). More precisely, we inspected the mean concentration of radioactivity in the brain over a period of 90 seconds following its arrival, and used this as a surrogate for rCBF. Here, we will refer to this surrogate as rCBF. Regions of interest (ROIs) were derived from the $\mathrm{n} 30 \mathrm{r} 83$ version of the probabilistic brain-atlas by Hammers et al. (2003) (Hammers et al., 2003; Rylands et al., 2012), and were selected based upon significant results found in the afore-mentioned whole-brain analysis. 


\section{RESULTS}

\subsection{Effects of DBS on rCBF: whole-brain analysis}

\subsubsection{Baseline versus stimulation on}

Compared to baseline, significant $\mathrm{rCBF}$ decreases in the NAcc were seen after stimulation of both $\operatorname{Cg} 25$ [MNI coordinates $x, y, z$ (in mm) $=14,12,-1$; cluster size $(k)=31 ; p F W E c<0.001]$ and $\operatorname{Cg} 24$ [14, 10, $-7 ; \mathrm{k}=23 ; \mathrm{pFWEc}<0.001]$. With combined target stimulation, $\mathrm{rCBF}$ increased in the post-central gyrus $[44,-24,61 ; k=113 ; p F W E c<0.001]$ and parietal sub-gyral area $[24,-42,57 ; k=60$; pFWEc $<0.001]$.

\subsubsection{Baseline versus stimulation off}

Compared to baseline, significant rCBF increases were seen in the post-central gyrus [44, -24, 59; $k=84 ; p F W E c<0.001]$ and parietal sub-gyral area $[26,-40,53 ; k=35 ; p F W E c<0.001]$ when combined stimulation was acutely switched off, similar to the findings in baseline versus stimulation on (3.1.1, above). A significant $\mathrm{rCBF}$ increase in the dorsal anterior cingulate (ACC) was seen when chronic VAC stimulation was acutely switched off $[10,32,19 ;(k)=57 ; p F W E c<0.001]$.

\subsubsection{Acute interruption of chronic stimulation: on versus off}

When comparing rCBF on chronic stimulation with $\mathrm{rCBF}$ after stimulation had been turned off for 120 minutes (acute effects), only one statistically significant result was found: rCBF increased in the dorsal ACC when VAC stimulation was switched off $[12,30,31 ; k=31 ; p F W E c<0.001]$. This is similar to the rCBF increase in VAC seen between baseline and stimulation off (3.1.2, above). 
Further details of all significant DBS effects comparing baseline with on and off, and on versus off, stratified by target stimulated ( $\mathrm{Cg} 25, \mathrm{Cg} 24, \mathrm{VAC}, \mathrm{NAcc}$, and any combination of more than one target stimulated) are presented in Supplement 1. DBS signal changes compared to baseline on the normalized SPM glass brain are presented in Supplement 2.

\subsubsection{Effects of chronic stimulation of each area}

In the whole-brain results above, similar findings were apparent when comparing stimulation on and off with baseline, and few effects were seen when chronic stimulation was acutely interrupted. We therefore decided to run additional analyses, focusing on effects between: (i) baseline and SGC stimulation (Cg25+Cg24); (ii) baseline and VAC/NAcc (VAC+NAcc) stimulation, and (iii) baseline and combined target stimulation, all regardless of whether stimulation was on or off. Please see Table 3 for the results.

--- Table 3 ---

\subsection{Region data on NAcc}

The most consistent finding after visually inspecting the ROI data was a decrease in rCBF (regional/global CBF) in TRD patients in the NAcc. This decrease was apparent irrespective which target was stimulated. Also, differences between both baseline and on, and baseline and off were overall more pronounced than differences between on and off (Figure 2).

--- Figure 2 ---

We also see a decrease in NAcc rCBF when inspecting the data over time (from baseline to visit 4), regardless of target stimulation (Figure 3). Furthermore, post-hoc whole-brain SPM analysis of DBS 
signal-changes between baseline and visit 4 , when target stimulation is optimized, showed a similar decrease in NAcc, and a decrease encompassing $\mathrm{Cg} 25, \mathrm{ACC}$ (ba32) and the interpeduncular region of the ventral midbrain (Figure 4).

\section{--- Figure 3 ---}

--- Figure 4 ---

\subsection{Effects in PFC and clinical outcomes}

Over the course of the study, 3 patients remitted, 2 responded but did not remit (non-remitters), and 2 were non-responders. When visually inspecting the ROI data over time, there was an increase in rCBF bilaterally in the PFC. The data indicated that remitters had higher rCBF in the PFC both at baseline and all subsequent visits compared to non-remitters and non-responders (Figure $5 a-b$ ).

Although less clear, when looking at the raw data of clinical outcome measures, remitters also seemed to have lower MADRS and HAM-D scores at baseline (indicating less severe depression) (Figure $5 c-d$ ). They also had higher GAF scores (indicating less impaired social, occupational, and psychological functioning) during baseline (Figure 5e). 
Deep brain stimulation in TRD

\section{DISCUSSION}

The present study was conducted to compare stimulation of SGC (Cg25 or Cg24), VAC/NAcc (VAC or NAcc), and a combination of these targets in the same TRD patients, focusing on both acute and chronic changes in $\mathrm{rCBF}$ using $\left[{ }^{15} \mathrm{O}\right]$ water PET. DBS was associated with decreased $\mathrm{rCBF}$ at the sites of stimulation and in a range of distant regions including frontal and orbitofrontal cortical regions and thalamus (Table 3). Most prominently, a decrease in NAcc was seen with all three stimulation conditions. Acute interruption of chronic stimulation was not associated with prominent $\mathrm{rCBF}$ changes (Supplement 1). Five of seven patients responded to DBS and of these, three remitted. These results are similar to previous studies (Lozano et al., 2008) (Bewernick et al., 2010). Remitters had higher rCBF in PFC before and throughout DBS (Figure 5).

\subsection{Acute effects}

The lack of prominent changes after acute interruption of chronic stimulation might be caused by the relatively short time ( 2 hours) that stimulation was switched off before scanning. A previous study suggests that beneficial DBS effects in dystonia may persist after stimulation is switched off, with only a slow worsening of symptoms returning to pre-operative levels after 48 hours of stimulation (Grabli et al., 2009). In agreement, a case-report of a TRD patient under DBS of the lateral habenula showed that after stimulation was accidentally switched off, relapse occurred a couple of days later (Sartorius et al., 2010). One might however expect that stimulation interruption would cause acute changes in rCBF even when not apparent in behavioral response. But in this study, in general, this was not observed. Nonetheless, such acute rCBF changes may still occur when switching stimulation acutely on. 
4.2 Effects by area of stimulation

\subsubsection{Effects on frontal regions and thalamus}

Local rCBF decreases were apparent in Cg25 after SGC stimulation and in NAcc after SGC, VAC/NAcc, and combined stimulation. Increases in both glucose metabolism and rCBF in SGC have been seen in MDD, which normalize with remission and antidepressant treatment (Sacher et al., 2012; Drevets et al., 2008; Mayberg et al., 1999). In more distant regions, decreases in medial frontal gyrus and thalamus were seen with SGC and combined stimulation, and in the MFG with SGC and VAC/NAcC stimulation. Decreases in the orbitofrontal cortex were present after combined stimulation. In keeping with this, decreases in the medial frontal gyrus and orbitofrontal cortex after DBS have previously been reported with both Cg25 (Lozano et al., 2008; Mayberg et al., 2005) and NAcc stimulation (Bewernick et al., 2012; Millet et al., 2014). Similar effects have also been observed after $\mathrm{CBT}$, suggesting that SGC and combined DBS target a mood-regulatory network involved in depression (Mayberg et al., 2005). Additionally, the effects seen in the MFG are consistent with past studies regarding Cg25 stimulation (Lozano et al., 2008), and in the thalamus regarding NAcc stimulation (Bewernick et al., 2010; Schlaepfer et al., 2008).

Increases in rCBF were only observed after combined DBS, with effects in MFG, pre-and postcentral gyrus, and inferior- and superior gyrus. Increases in MFG are comparable to previous Cg25 and NAcc stimulation (Lozano et al., 2008; Schlaepfer et al., 2008). Precentral-, and superior gyrus increases are similar to NAcc stimulation in earlier studies (Bewernick et al., 2010; Millet et al., 2014). Increases in prefrontal regions, such as the inferior frontal gyrus, have been reported with $\mathrm{Cg} 25$ stimulation and are similar to antidepressant patterns seen with medication (Mayberg et al., 2005; Mayberg et al., 2000).

Taken together, our data are consistent with previous studies and indicate that abnormalities observed in MDD, such as hypo- and hyperactivity in brain regions (Morishita et al., 2014), are 
Deep brain stimulation in TRD

reversed by DBS. Our results show that the targets used have more commonalities than differences between them with an overlap in effects between stimulation targets, which is also present when comparing Cg25 and NAcc literature, suggesting a similar response-pattern irrespective of target area.

\subsubsection{Effects on NAcc}

A decrease in NAcc rCBF is also apparent in the region data with all target stimulations (Figure 2), consistent with the NAcc results of our whole-brain analysis (Table 2). Furthermore, no clear difference between stimulation on or off can be seen which is again consistent with earlier analysis (Appendix 1). When looking at the response pattern over time, the rCBF decrease in the NAcc remains (Figure 3) which is also consistent with whole-brain analysis (Figure 4). This decrease in NAcc rCBF does not appear to differ between responders and non-responders, suggesting that this decrease is either not directly linked to improvement of MDD symptoms, or on its own is insufficient for response.

Previous DBS studies do not report NAcc decreases. In fact an increase in NAcc metabolism has been reported after 1 week of NAcc DBS (Schlaepfer et al., 2008). However, this increase did not remain after chronic DBS suggesting that it might have been a short-term response to the surgical procedure (Bewernick et al., 2012).

\subsection{Frontal cortical changes predictive for response and marker for response}

Our stimulation procedures were designed to ensure that patients received appropriate DBS of either SGC or VAC/NAcc during treatment-period 1 and 2. During treatment-period 3, patients 
Deep brain stimulation in TRD

received combined DBS treatment or, when remission occurred in previous periods, the best treatment so far. It was therefore expected that improvements should be most prominent after the third treatment-period. Indeed, inspecting the region data over time shows increases in PFC between baseline and last PET scan (Figure 5). MDD is associated with decreased PFC activity and increases after DBS are consistent with past studies, as well as similar to effects of antidepressant medication (Mayberg et al., 2000; Mayberg et al., 2005; Schlaepfer et al., 2008). Activity changes in the PFC thus seem to be a marker of antidepressant response (Riva-Posse et al., 2014).

Our data show that remitters had higher rCBF levels in the PFC during all visits, including baseline, compared to non-remitters and non-responders. Remitters also had relatively better clinical outcome measures at baseline and at the last PET visit. Higher frontal cortical rCBF might thus be predictive for response. However, even though non-responders failed to cross the clinical threshold, effects of DBS were apparent. It might therefore be that DBS on its own is insufficient or that more time on stimulation is required to reach clinical response in these patients, which are in this study characterized by low PFC rCBF.

\subsection{Limitations}

A limitation of our study is the small sample size that provides insufficient power to clearly determine clinical efficacy, making our findings preliminary. Nonetheless, 5 of 7 patients responded to TRD and 3 of 7 reached remission. Given the documented low and poorly sustained response rates in TRD (Dunner et al., 2006; Luigjes et al., 2013), these are encouraging results. In this study, patients were required to have failed to respond to two courses of ECT, or responded only to maintenance ECT, or did not respond to a first course of ECT and were unwilling to have a further course. Our cohort of patients therefore represents a particularly treatment-refractory group. 
Deep brain stimulation in TRD

Recently proposed standardised definitions of TRD, including "Stage II treatment-resistant depression" (Conway et al., 2017)and "Multiple-therapy-resistant-Major Depressive Disorder" (MTRMDD) (McAllister-Williams et al., 2017 (in press)), which may warrant more invasive or higher-risk antidepressant treatments such as surgical interventions, either do not include the need for prior ECT (Stage-II TRD) or require non-response to one adequate trial of ECT (MTR-MDD). Standardisation of inclusion criteria should improve the comparability of future studies. Additionally, it might have been better to determine the ideal stimulation sites and frequencies for each patient over a longer period than two days per contact, since it may take longer to see the ideal effects of DBS. However, we did notice differences in improvements between stimulation sites and frequencies after trying each contact in turn for up to two days, making this approach nonetheless an improvement and appealing approach for future DBS studies. Another limitation is that stimulation was always switched off after chronic stimulation, though acute changes might occur if stimulation were to be acutely switched on after being off. Global intensity-normalization was used, meaning that rCBF changes in one direction could be due to changes in the opposite direction of the complementary region. Furthermore, no sham stimulation phase was used because of possible symptom aggravation. Indeed, previous studies have changed their design after study-initiation leaving out sham conditions because of significant worsening of symptoms (Bewernick et al., 2010; Bewernick et al., 2012; Holtzheimer et al., 2012). Moreover, there is evidence that placebo response rates are lower in patients with severe depression (such as in our cohort) compared to patients with mild depression (Schatzberg and Kraemer, 2000). Also, for each of our patients different stimulation contacts and frequencies for stimulation were most effective, arguing for specificity of stimulation (Lozano et al., 2008).

\subsection{Conclusion}


We conclude that DBS improves TRD in the majority of patients. Acute effects of short-term DBS interruption are small compared to chronic stimulation effects, indicating that acute effects are more subtle than hypothesized. A consistent decrease in $\mathrm{rCBF}$ is observed in the NAcc with DBS regardless of stimulation site, suggesting that this may be a common pathway mediating effects of DBS in TRD, although it is not clearly linked to improvement in severity of depression. Our data additionally suggest that treatment response is reached in patients with higher baseline prefrontal rCBF. Further evaluation is necessary to confirm whether higher frontal rCBF could be a predictive biomarker of treatment response, which might help to optimize patient selection for DBS in MDD. 
Deep brain stimulation in TRD

\section{ACKNOWLEDGEMENTS}

The authors acknowledge the contributions of Dr Andrea Malizia to the design and conduct of the clinical trial to which these patients were recruited; PET radiographers Campbell McCullough, Mike Godfrey, Eleanor Duncan-Rouse and Gerrit Helms van der Vegte; Robin Holmes for data processing; and other staff at the Wolfson Molecular Imaging Centre. We thank the patients for their participation. The study is registered under Clinical Trials registration: NCT01435148. 


\section{CONFLICTS OF INTEREST}

S.C. has been a consultant for Bayer HealthCare LLC. N.K.P. has been medical advisor to Boston Scientific and has held consultancies to Medtronic, St Jude Medical (now Abbott) and Nevro; and he is the chief medical officer at Bioinduction Ltd (Bristol, United Kingdom). PST has received consultancy fees as an Advisory Board member for the following companies: Galen Limited; Sunovion Pharmaceuticals Europe Ltd; myTomorrows; Cyberonics Europe BVBA (now LivaNova UK Ltd). J.C.M. and J.A. have no conflict of interest. 
Deep brain stimulation in TRD

\section{REFERENCES}

Berlim MT, McGirr A, Van den Eynde F, et al. (2014) Effectiveness and acceptability of deep brain stimulation (DBS) of the subgenual cingulate cortex for treatment-resistant depression: a systematic review and exploratory meta-analysis. J Affect Disord 159: 31-38.

Bewernick BH, Hurlemann R, Matusch A, et al. (2010) Nucleus accumbens deep brain stimulation decreases ratings of depression and anxiety in treatment-resistant depression. Biol Psychiatry 67: 110-116.

Bewernick BH, Kayser S, Sturm V, et al. (2012) Long-term effects of nucleus accumbens deep brain stimulation in treatment-resistant depression: evidence for sustained efficacy. Neuropsychopharmacology 37: 1975-1985.

Committee JF. (2015) British National Formulary, London: BMJ Group and Pharmaceutical Press.

Comtat C, Bataille F, Michel C, et al. (2004) OSEM-3D reconstruction strategies for the ECAT HRRT. Nuclear Science Symposium Conference Record. IEEE, 3492-3496.

Conway CR, George MS and Sackeim HA. (2017) Toward an Evidence-Based, Operational Definition of Treatment-Resistant Depression: When Enough Is Enough. JAMA Psychiatry 74: 9-10.

Drevets WC, Savitz J and Trimble M. (2008) The subgenual anterior cingulate cortex in mood disorders. CNS Spectr 13: 663-681.

Dunner DL, Rush AJ, Russell JM, et al. (2006) Prospective, long-term, multicenter study of the naturalistic outcomes of patients with treatment-resistant depression. J Clin Psychiatry 67: 688-695.

Grabli D, Ewenczyk C, Coelho-Braga MC, et al. (2009) Interruption of deep brain stimulation of the globus pallidus in primary generalized dystonia. Mov Disord 24: 2363-2369.

Hall RC. (1995) Global assessment of functioning. A modified scale. Psychosomatics 36: 267-275.

Hamilton M. (1960) A rating scale for depression. J Neurol Neurosurg Psychiatry 23: 56-62. 
Hammers A, Allom R, Koepp MJ, et al. (2003) Three-dimensional maximum probability atlas of the human brain, with particular reference to the temporal lobe. Hum Brain Mapp 19: 224-247.

Holtzheimer PE, Kelley ME, Gross RE, et al. (2012) Subcallosal cingulate deep brain stimulation for treatment-resistant unipolar and bipolar depression. Arch Gen Psychiatry 69: 150-158.

Kennedy SH, Giacobbe P, Rizvi SJ, et al. (2011) Deep brain stimulation for treatment-resistant depression: follow-up after 3 to 6 years. Am J Psychiatry 168: 502-510.

Khan S, Javed S, Park N, et al. (2010) A magnetic resonance imaging-directed method for transventricular targeting of midline structures for deep brain stimulation using implantable guide tubes. Neurosurgery 66: 234-237; discussion 237.

Krishnan V and Nestler EJ. (2010) Linking molecules to mood: new insight into the biology of depression. Am J Psychiatry 167: 1305-1320.

Kubu CS, Malone DA, Chelune G, et al. (2013) Neuropsychological outcome after deep brain stimulation in the ventral capsule/ventral striatum for highly refractory obsessivecompulsive disorder or major depression. Stereotact Funct Neurosurg 91: 374-378.

Lozano AM, Mayberg HS, Giacobbe P, et al. (2008) Subcallosal cingulate gyrus deep brain stimulation for treatment-resistant depression. Biol Psychiatry 64: 461-467.

Luigjes J, de Kwaasteniet BP, de Koning PP, et al. (2013) Surgery for psychiatric disorders. World Neurosurg 80: S31 e17-28.

Malone DA, Jr., Dougherty DD, Rezai AR, et al. (2009) Deep brain stimulation of the ventral capsule/ventral striatum for treatment-resistant depression. Biol Psychiatry 65: 267-275.

Mayberg HS, Brannan SK, Tekell JL, et al. (2000) Regional metabolic effects of fluoxetine in major depression: serial changes and relationship to clinical response. Biol Psychiatry 48: 830-843.

Mayberg HS, Liotti M, Brannan SK, et al. (1999) Reciprocal limbic-cortical function and negative mood: converging PET findings in depression and normal sadness. Am J Psychiatry 156: 675682. 
Deep brain stimulation in TRD

Mayberg HS, Lozano AM, Voon V, et al. (2005) Deep brain stimulation for treatment-resistant depression. Neuron 45: 651-660.

McAllister-Williams RH, Christmas DMB, Cleare AJ, et al. (2017 (in press)) Multiple-therapy-resistantMajor Depressive Disorder (MTR-MDD): a clinically important concept. Br J Psychiatry 2017 (in press).

Millet B, Jaafari N, Polosan M, et al. (2014) Limbic versus cognitive target for deep brain stimulation in treatment-resistant depression: accumbens more promising than caudate. Eur Neuropsychopharmacol 24: 1229-1239.

Montgomery SA and Asberg M. (1979) A new depression scale designed to be sensitive to change. $\mathrm{Br}$ J Psychiatry 134: 382-389.

Morishita T, Fayad SM, Higuchi MA, et al. (2014) Deep brain stimulation for treatment-resistant depression: systematic review of clinical outcomes. Neurotherapeutics 11: 475-484.

Nauczyciel C, Robic S, Dondaine T, et al. (2013) The nucleus accumbens: a target for deep brain stimulation in resistant major depressive disorder. J Mol Psychiatry 1: 17.

Patel NK, Plaha P and Gill SS. (2007) Magnetic resonance imaging-directed method for functional neurosurgery using implantable guide tubes. Neurosurgery 61: 358-365; discussion 365-356.

Puigdemont D, Perez-Egea R, Portella MJ, et al. (2012) Deep brain stimulation of the subcallosal cingulate gyrus: further evidence in treatment-resistant major depression. Int J Neuropsychopharmacol 15: 121-133.

Riva-Posse P, Choi KS, Holtzheimer PE, et al. (2014) Defining critical white matter pathways mediating successful subcallosal cingulate deep brain stimulation for treatment-resistant depression. Biol Psychiatry 76: 963-969.

Rylands AJ, Hinz R, Jones M, et al. (2012) Pre- and postsynaptic serotonergic differences in males with extreme levels of impulsive aggression without callous unemotional traits: a positron emission tomography study using (11)C-DASB and (11)C-MDL100907. Biol Psychiatry 72: 1004-1011. 
Sacher J, Neumann J, Funfstuck T, et al. (2012) Mapping the depressed brain: a meta-analysis of structural and functional alterations in major depressive disorder. J Affect Disord 140: 142148.

Sartorius A, Kiening KL, Kirsch P, et al. (2010) Remission of major depression under deep brain stimulation of the lateral habenula in a therapy-refractory patient. Biol Psychiatry 67: e9e11.

Schatzberg AF and Kraemer HC. (2000) Use of placebo control groups in evaluating efficacy of treatment of unipolar major depression. Biol Psychiatry 47: 736-744.

Schlaepfer TE and Bewernick BH. (2013) Deep brain stimulation for major depression. Handb Clin Neurol 116: 235-243.

Schlaepfer TE, Cohen MX, Frick C, et al. (2008) Deep brain stimulation to reward circuitry alleviates anhedonia in refractory major depression. Neuropsychopharmacology 33: 368-377.

World Health Organization. (2016) Depression fact Sheet. Available from: http://www.who.int/mediacentre/factsheets/fs369/en/ 

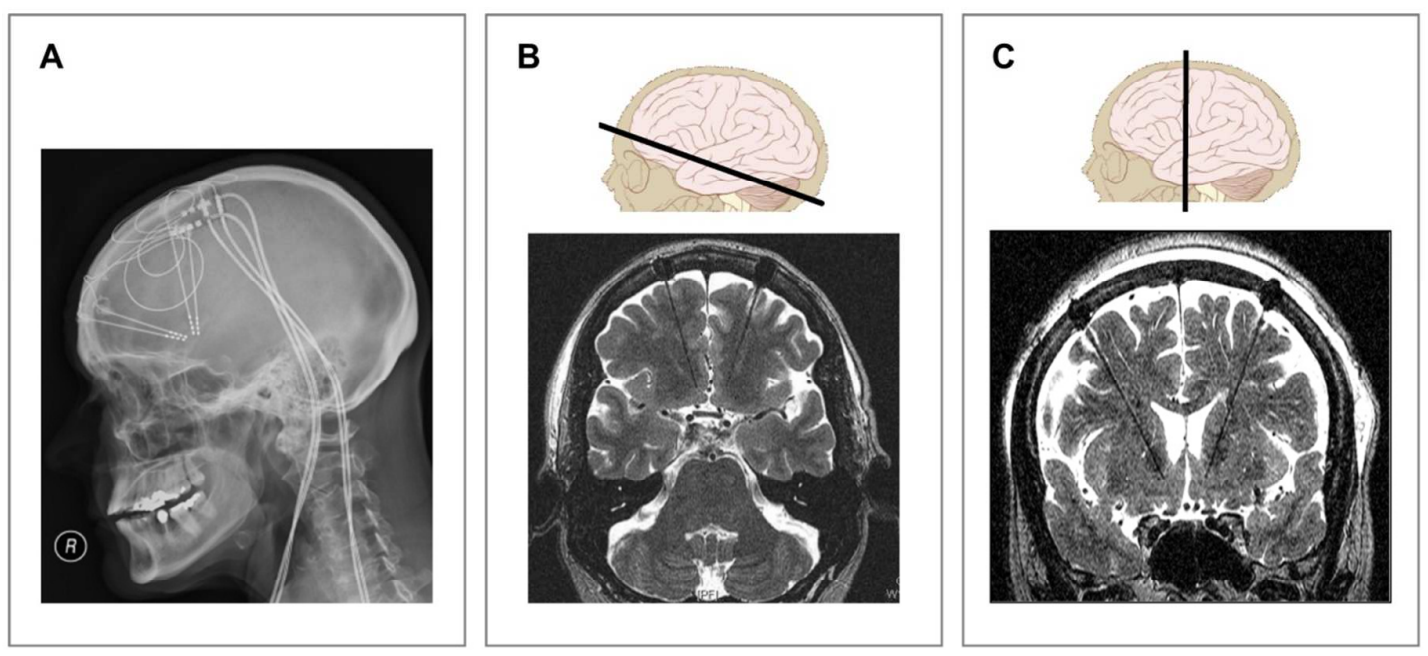


\section{Nucleus Accumbens}

6
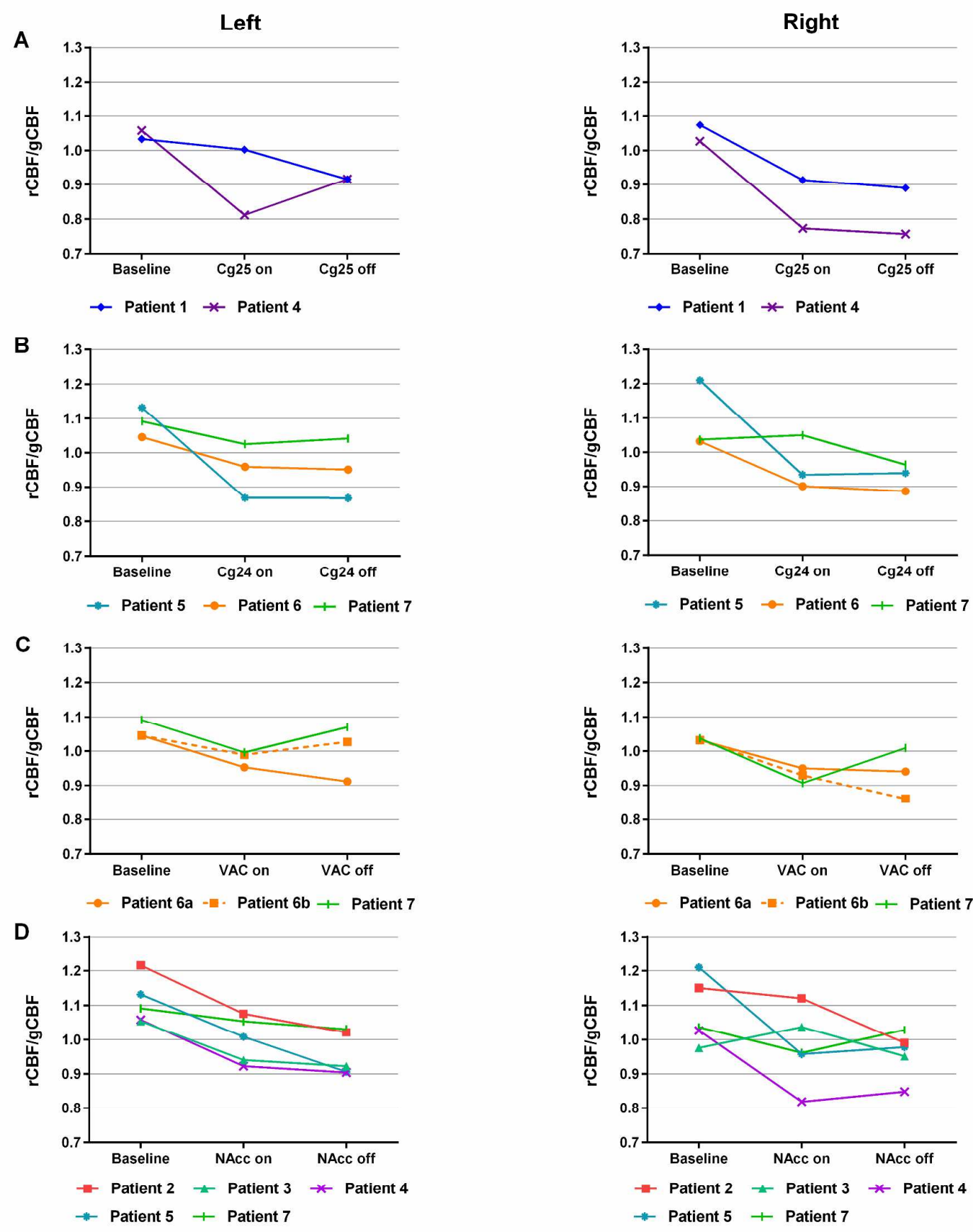

- Patient $6 a-$ - Patient $6 b+$ Patient 7
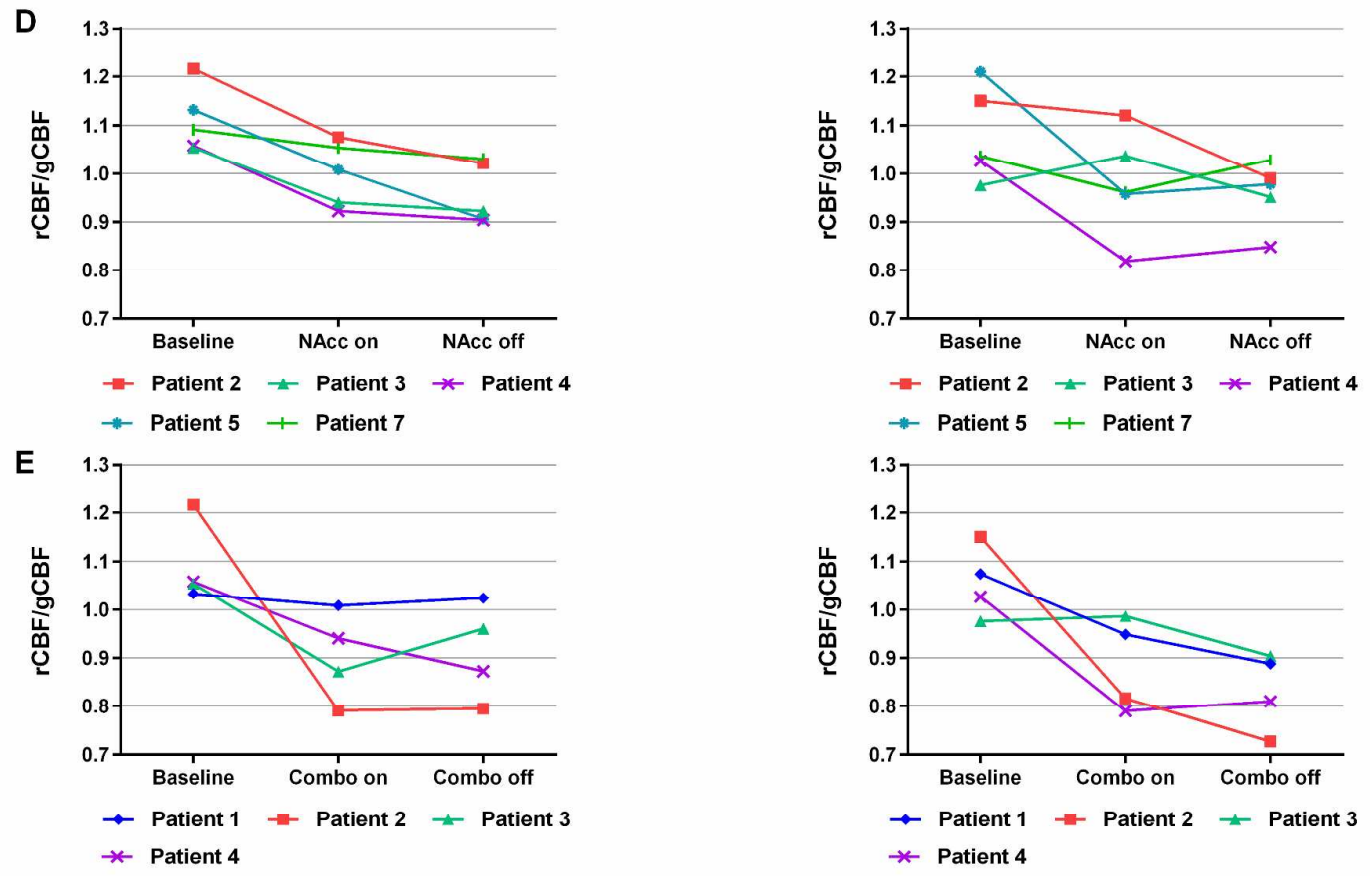


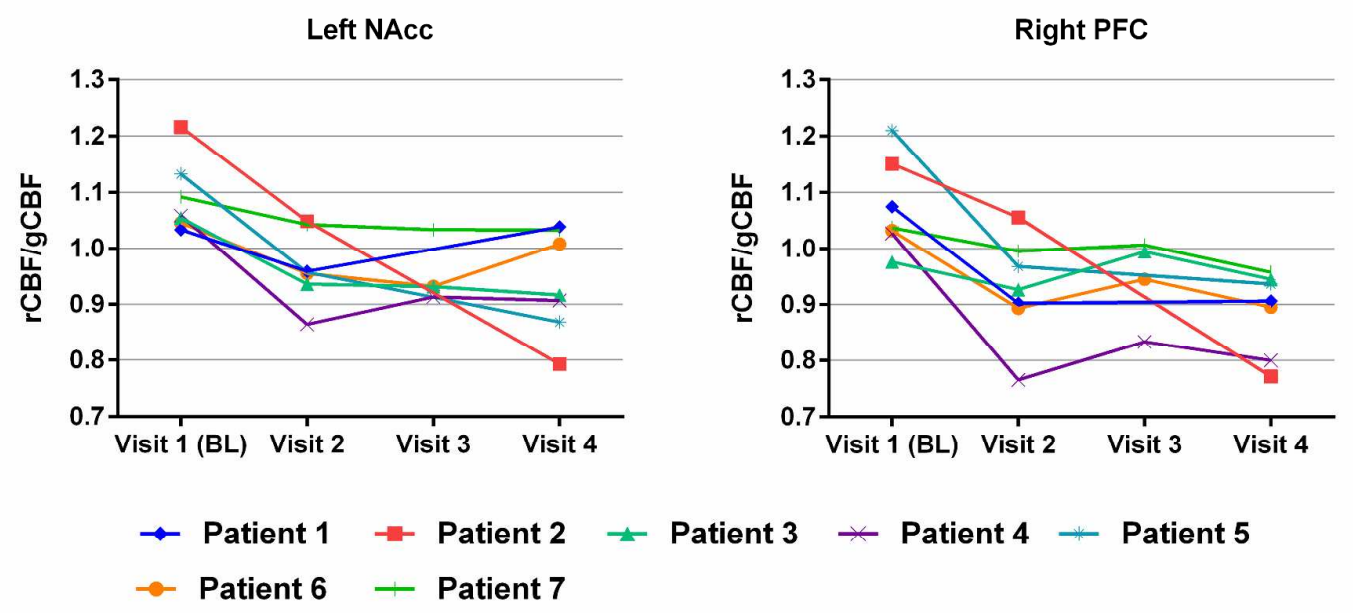




\section{Baseline $>$ visit 4}

A

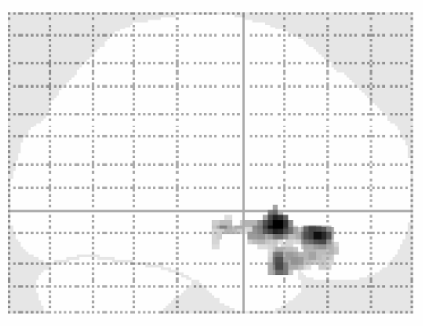

B

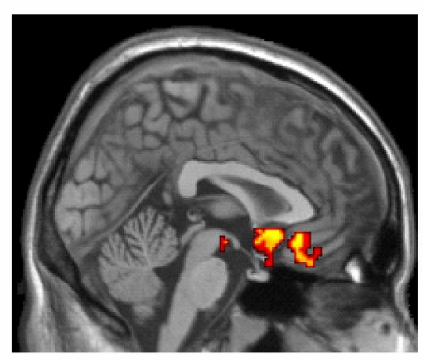

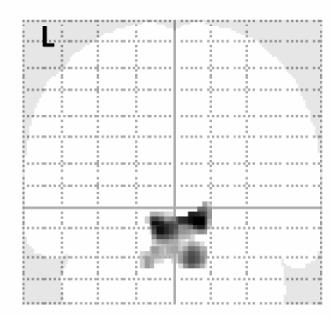
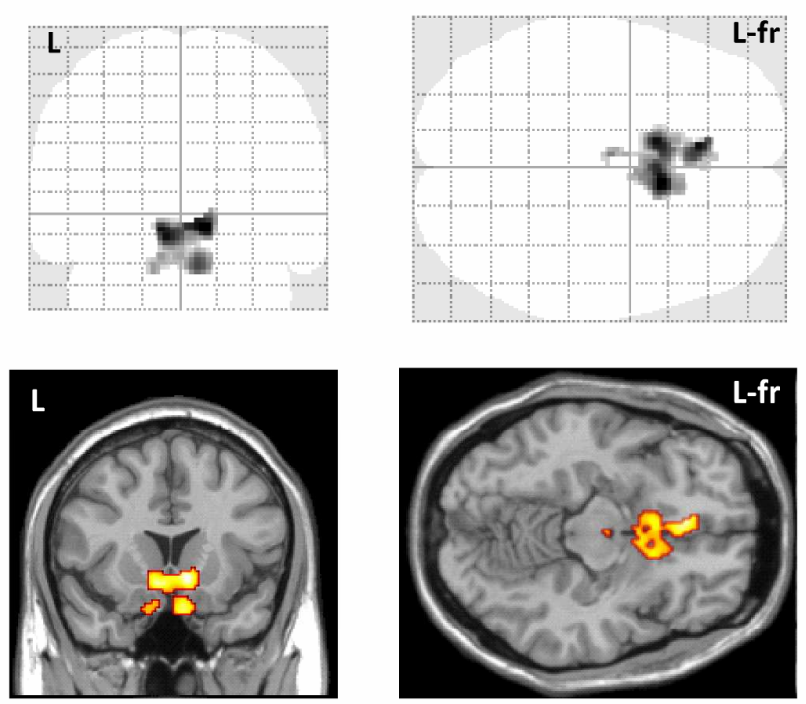

23

25

26

27

28

30

31

32

33

34

36

37

38

39

40

41

42

44

45

46

47

48

49

51

52

53

54

55

56

57

59

60

http://mc.manuscriptcentral.com/jop 
Left PFC

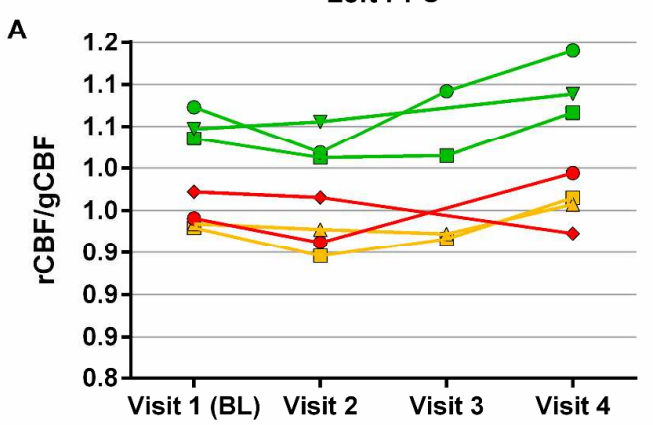

MADRS

C

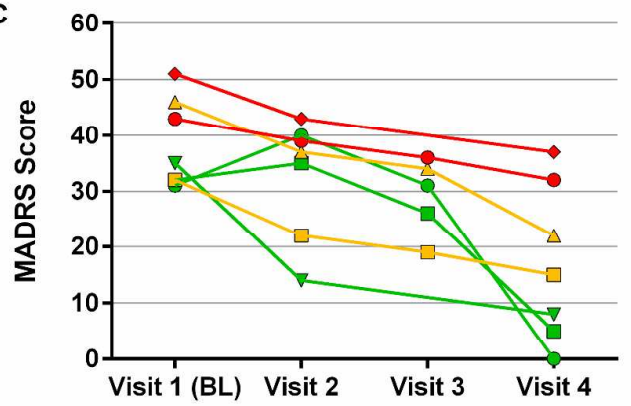

E

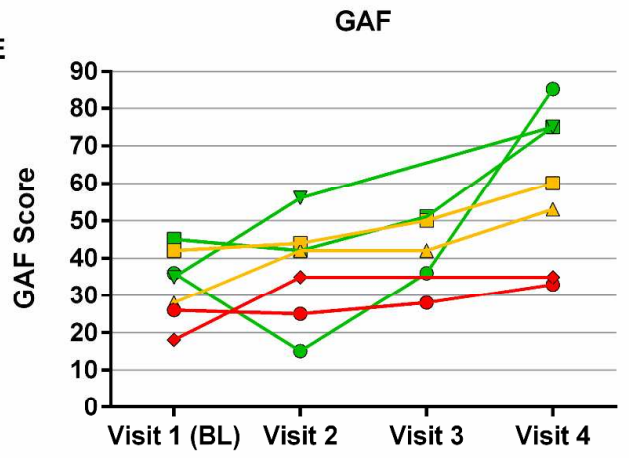

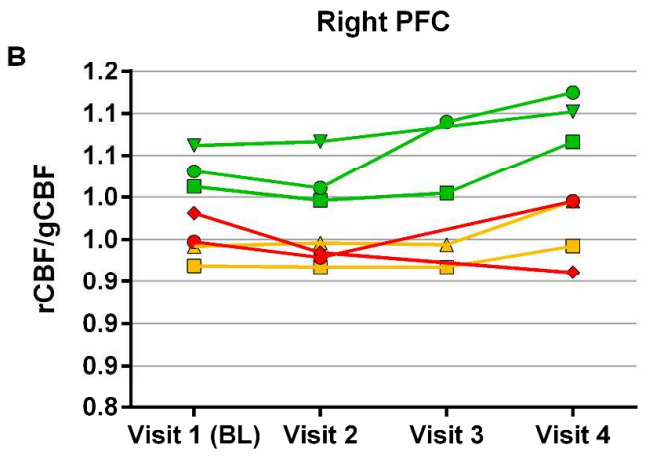
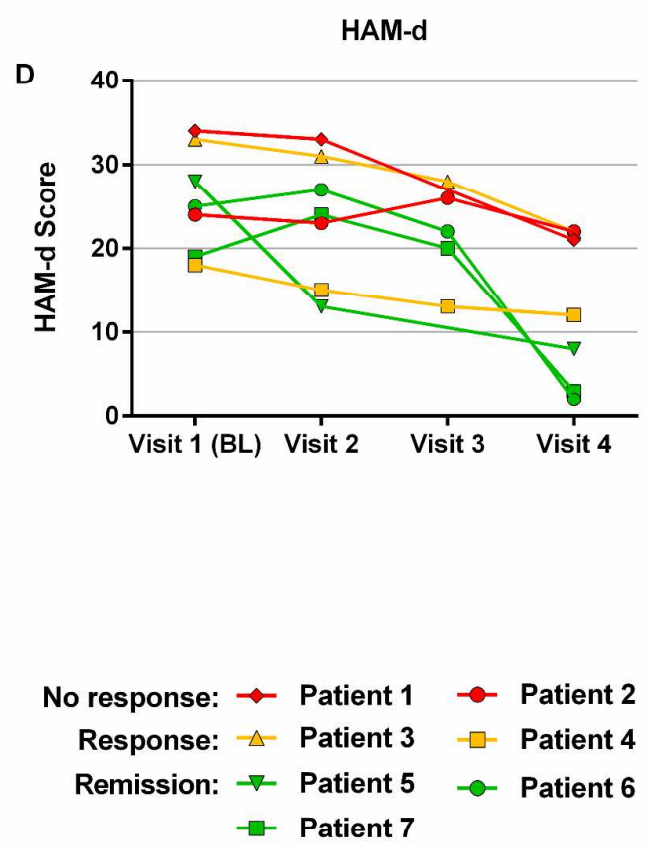


\begin{tabular}{|c|c|c|c|c|c|c|c|c|c|c|c|}
\hline & $\begin{array}{c}\text { Visit 1 } \\
\text { (baseline) }\end{array}$ & $\begin{array}{c}\text { Stereotactic } \\
\text { surgery }\end{array}$ & $\begin{array}{c}\text { DBS 1 } \\
>3 \text { months }\end{array}$ & \multicolumn{2}{|c|}{ Visit 2} & $\begin{array}{c}\text { DBS 2 } \\
>3 \text { months }\end{array}$ & \multicolumn{2}{|c|}{ Visit 3} & $\begin{array}{c}\text { DBS } 3 \\
>3 \text { months } \\
\end{array}$ & \multicolumn{2}{|c|}{ Visit 4} \\
\hline PET scan & -4284 & & & 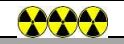 & -248 & & $2+2$ & 282 & & 284 & -24 \\
\hline Stimulation on & $\mathrm{n} / \mathrm{a}$ & & & & & & & & & & \\
\hline Site & & & \multicolumn{3}{|c|}{ Cg24, Cg25, NAcc or VAC } & \multicolumn{3}{|c|}{$\operatorname{Cg} 24, \operatorname{Cg} 25$, NAcc or VAC* } & \multicolumn{3}{|c|}{ Cg24, Cg25, NAcc, VAC, or combo* } \\
\hline
\end{tabular}




\begin{tabular}{llcccccc}
\hline & Region & Side & pFWEc & k & $\mathbf{x}$ & y & z \\
\hline BL > SGC & Nucleus accumbens/subgenual & - & 0.000 & & & & \\
& anterior cingulate (ba25) & & & 1160 & 14 & 12 & -3 \\
& Medial frontal gyrus (ba10) & $\mathrm{R}$ & 0.000 & 50 & 18 & 58 & 5 \\
& Middle frontal gyrus (ba8) & $\mathrm{L}$ & 0.000 & 62 & -46 & 22 & 47 \\
& Medial frontal gyrus (ba10) & $\mathrm{L}$ & 0.000 & 44 & -2 & 60 & 1 \\
& Thalamus & $\mathrm{R}$ & 0.000 & 46 & 4 & -12 & 1 \\
\hline BL > VAC/NAcc & Subgenual anterior cingulate & $\mathrm{R}$ & 0.000 & & & & \\
& (ba32) & & & 32 & 10 & 12 & -9 \\
& Nucleus accumbens & $\mathrm{L}$ & 0.000 & 57 & -4 & 28 & -9 \\
& Nucleus accumbens & $\mathrm{L}$ & 0.000 & 60 & -8 & 16 & -11 \\
& Middle frontal gyrus (ba8) & $\mathrm{L}$ & 0.000 & 30 & -36 & 22 & 43 \\
\hline BL > combination & Nucleus accumbens & - & 0.000 & 135 & 10 & 12 & -9 \\
& Thalamus & $\mathrm{L}$ & 0.000 & 66 & -4 & -10 & 11 \\
& Orbital gyrus (ba11) & $\mathrm{R}$ & 0.000 & 91 & 4 & 44 & -27 \\
& Medial frontal gyrus (ba11) & $\mathrm{L}$ & 0.000 & 42 & -8 & 30 & -13 \\
& Rectal gyrus (ba11) & $\mathrm{R}$ & 0.000 & 30 & 6 & 14 & -23 \\
\hline BL < combination & Postcentral gyrus (ba3) & $\mathrm{R}$ & 0.000 & 730 & 44 & -24 & 59 \\
& Postcentral gyrus (ba1) & $\mathrm{L}$ & 0.000 & 174 & -48 & -22 & 59 \\
& Precentral gyrus (ba6) & $\mathrm{R}$ & 0.000 & 264 & 58 & -2 & 27 \\
& Precentral gyrus (ba6) & $\mathrm{R}$ & 0.000 & 92 & 14 & -16 & 67 \\
& Inferior frontal gyrus (ba46) & $\mathrm{R}$ & 0.000 & 103 & 46 & 34 & 3 \\
& Superior frontal gyrus & $\mathrm{L}$ & 0.000 & 42 & -26 & 50 & 1 \\
& Middle frontal gyrus (ba10) & $\mathrm{R}$ & 0.000 & 72 & 36 & 44 & 15 \\
& Middle frontal gyrus (ba10) & $\mathrm{L}$ & 0.000 & 38 & -34 & 42 & 21 \\
\hline
\end{tabular}


Deep brain stimulation in TRD

\section{Supplement 1}

S1. Overview of DBS effects compared with baseline, and on versus off, divided by area of stimulation. DBS effects were measured after area was stimulated for $>3$ months (electrode switched on), and after the electrode was switched off for 120 minutes after stimulation (electrode switched off). On = electrode switched on for at least 3 months. Off $=$ electrode switched off for 120 minutes after stimulation. $\mathrm{BL}=$ baseline, $\mathrm{Cg} 25=$ subgenual cingulate $25, \mathrm{Cg} 24=$ subgenual cingulate $24, \mathrm{VAC}=$ ventral anterior capsule, $\mathrm{NAcc}=$ nucleus accumbens, Combination = any other combination of more than 1 target stimulated. ba $=$ brodmann area. $\mathrm{k}=$ number of voxels. The data represent clusters ( $\mathrm{k}>30$ unilateral or $\mathrm{k}>15$ bilateral) of $p=0.05$, family-wise error (FWE) threshold, at a peak-level threshold of $p=0.05$ (FWE).

\begin{tabular}{|c|c|c|c|c|c|c|c|c|}
\hline & & Region & Side & PFWE & $\mathbf{k}$ & $\mathbf{x}$ & $y$ & $z$ \\
\hline \multirow[t]{4}{*}{$\operatorname{Cg} 25$} & $B L>$ on & Rectal gyrus (ba11) & $\mathrm{L}$ & 0.000 & 61 & -2 & 22 & -21 \\
\hline & & Nucleus accumbens & $\mathrm{R}$ & 0.000 & 31 & 14 & 12 & -1 \\
\hline & $B L>$ off & $\begin{array}{l}\text { Anterior cingulate } \\
\text { (ba32)/subgenual cingulate } \\
\text { (ba24) }\end{array}$ & $\mathrm{L}$ & 0.000 & 206 & -2 & 28 & -9 \\
\hline & & Medial frontal gyrus (ba25) & $\mathrm{R}$ & 0.000 & 65 & 10 & 12 & -13 \\
\hline \multirow[t]{3}{*}{$\operatorname{Cg} 24$} & $\mathrm{BL}>$ on & Nucleus accumbens & $\mathrm{R}$ & 0.000 & 23 & 14 & 10 & -7 \\
\hline & & Nucleus accumbens & L & 0.000 & 26 & -8 & 16 & -11 \\
\hline & $B L>$ off & Middle temporal gyrus (ba39) & $\mathrm{L}$ & 0.000 & 43 & -52 & -74 & 31 \\
\hline \multirow[t]{7}{*}{ VAC } & $B L>$ on & Cingulate gyrus (ba31) & $R$ & 0.000 & 62 & 10 & -40 & 41 \\
\hline & & Middle temporal gyrus (ba39) & $\mathrm{L}$ & 0.000 & 38 & -48 & -82 & 23 \\
\hline & $B L>$ off & Middle occipital gyrus (ba19) & L & 0.000 & 163 & -58 & -70 & 7 \\
\hline & & Middle occipital gyrus (ba18) & L & 0.000 & 36 & -42 & -90 & 11 \\
\hline & & $\begin{array}{l}\text { Superior temporal gyrus } \\
\text { (ba22) }\end{array}$ & L & 0.000 & 58 & -66 & -34 & 17 \\
\hline & $\mathrm{BL}<$ off & $\begin{array}{l}\text { Dorsal anterior cingulate } \\
\text { (ba32) }\end{array}$ & $\mathrm{R}$ & 0.000 & 57 & 10 & 32 & 19 \\
\hline & On $<$ off & $\begin{array}{l}\text { Dorsal anterior cingulate } \\
\text { (ba32) }\end{array}$ & $\mathrm{R}$ & 0.000 & 31 & 12 & 30 & 31 \\
\hline NAcc & $\mathrm{BL}>$ on & Superior frontal gyrus & $\mathrm{R}$ & 0.000 & 49 & 22 & 58 & 15 \\
\hline \multirow[t]{10}{*}{ Combination } & $\mathrm{BL}<$ on & Precentral gyrus (ba6) & $\mathrm{R}$ & 0.000 & 79 & 58 & -2 & 27 \\
\hline & & Postcentral gyrus (ba3) & $\mathrm{R}$ & 0.000 & 113 & 44 & -24 & 61 \\
\hline & & Postcentral gyrus (ba1) & L & 0.000 & 38 & -48 & -22 & 59 \\
\hline & & Parietal sub-gyral (ba40) & $\mathrm{R}$ & 0.000 & 60 & 24 & -42 & 57 \\
\hline & & Precentral gyrus (ba4) & $\mathrm{R}$ & 0.000 & 35 & 32 & -18 & 53 \\
\hline & & Inferior frontal gyrus (ba46) & $\mathrm{R}$ & 0.000 & 33 & 46 & 34 & 3 \\
\hline & $B L>$ off & Sub-lobar & $\mathrm{R}$ & 0.000 & 149 & 10 & 12 & -9 \\
\hline & $B L<$ off & Postcentral gyrus (ba3) & $\mathrm{R}$ & 0.000 & 84 & 44 & -24 & 59 \\
\hline & & Parietal sub-gyral (ba40) & $\mathrm{R}$ & 0.000 & 35 & 26 & -40 & 53 \\
\hline & & Middle frontal gyrus (ba10) & $\mathrm{R}$ & 0.000 & 38 & 36 & 44 & 13 \\
\hline
\end{tabular}




\section{Supplement 2}

A.

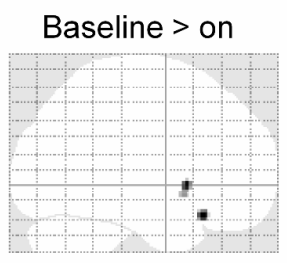

L

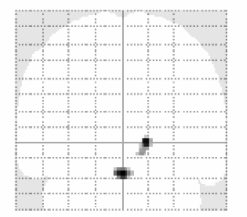

L-frontal

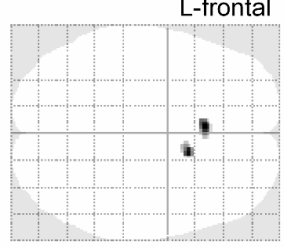

C.

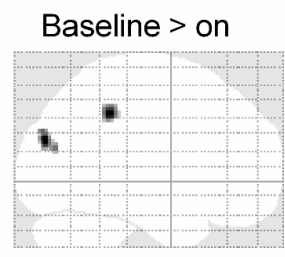

$\mathrm{L}$
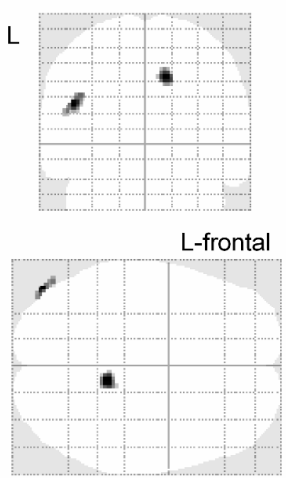

Cg25

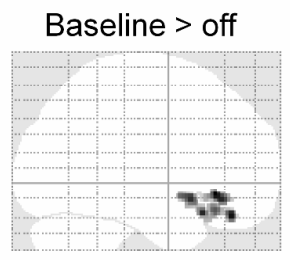

L
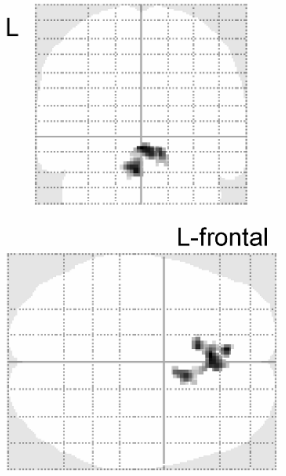

B.

\section{Cg24}
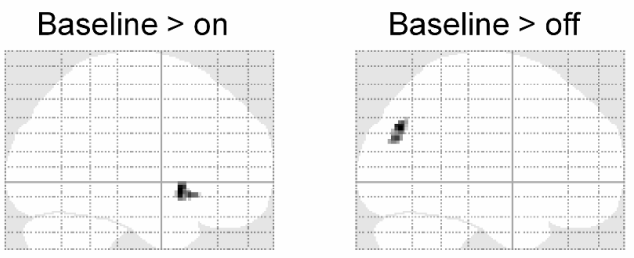

L
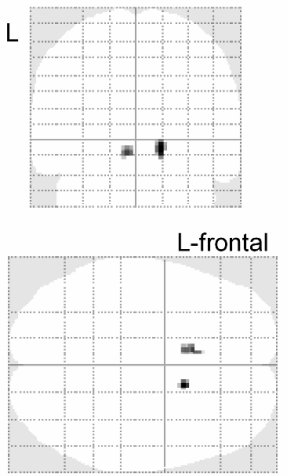

L
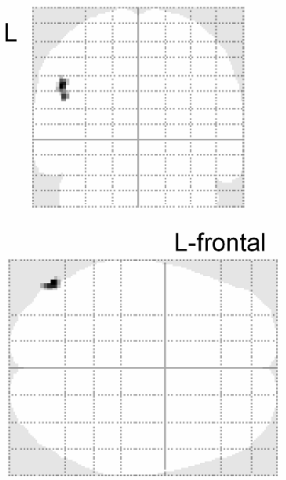

\section{VAC}
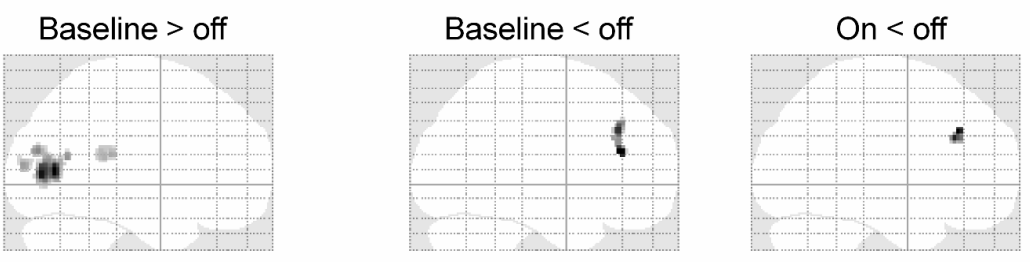

L
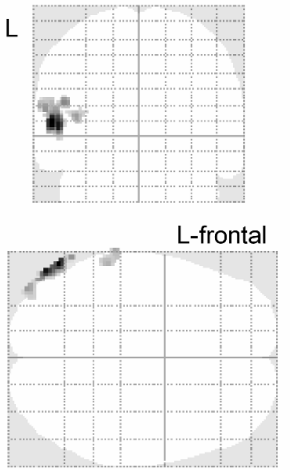

L
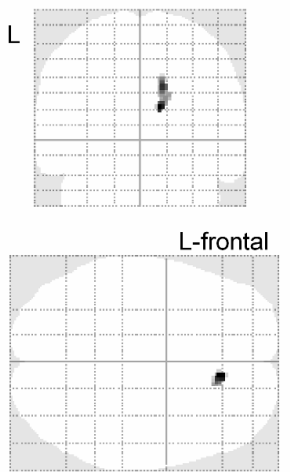

$\mathrm{L}$
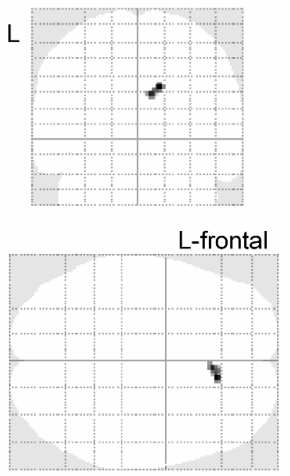

http://mc.manuscriptcentral.com/jop 
D. NAcc

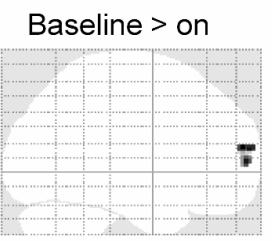

L

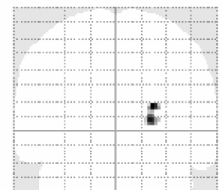

L-frontal

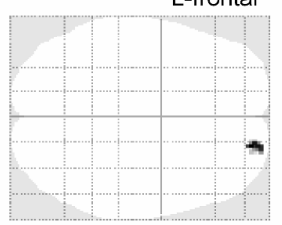

E.

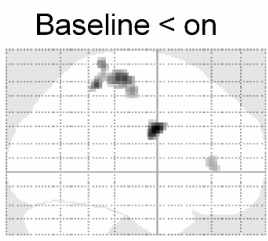

$\mathrm{L}$

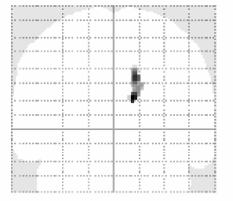

L-frontal

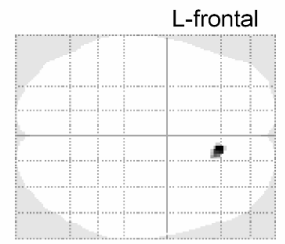

\section{Combination}

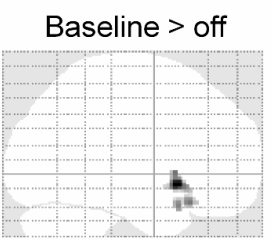

L

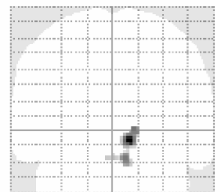

L-frontal

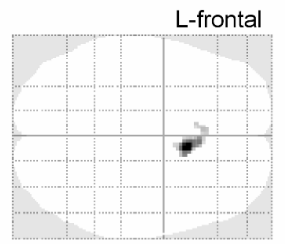

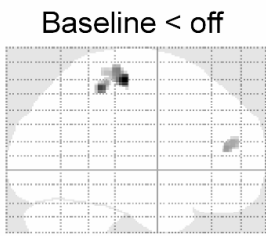

L
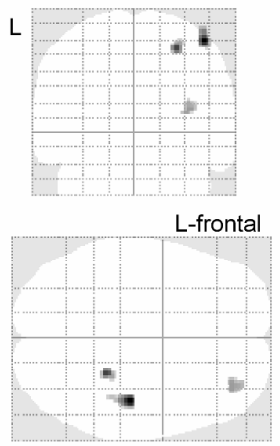

S2. DBS signal changes compared to baseline on the normalized SPM glass brain. Divided into 4 regions of activation: (a) subgenual cingulate 25 (Cg25), (b) subgenual cingulate 24 (Cg24), (c), ventral anterior capsule (VAC), (d) nucleus accumbens (NAcc), and (e) any other combination of more than 1 region stimulated (Combination). $L=$ left. 